\title{
İşyerinde Gelişmeleri Kaçırma Korkusu: Ölçek Uyarlama Çalışması
}

\section{The Fear of Missing Out (FoMO) in the Workplace: Scale Adaptation Study}

\author{
Seyhan Özdemir a,* \\ a Arş. Gör. Dr., Süleyman Demirel Üniversitesi, İktisadi ve İdari Bilimler Fakültesi, İşletme Bölümü, Isparta/Türkiye. \\ ORCID: 0000-0002-3530-6689
}

\section{MAKALE BILLGISİ}

\section{Makale Geçmişi:}

Başvuru tarihi: 01 Temmuz 2020

Düzeltme tarihi: 02 Aralık 2020

Kabul tarihi: 08 Aralık 2020

\section{Anahtar Kelimeler:}

Gelişmeleri Kaçırma Korkusu

GKK

İşyerinde FoMO

Çalışanlar

Ölçek Uyarlama

\section{ARTICLE INFO}

\section{Article history:}

Received 01 July 2020

Received in revised 02 December 2020

Accepted 08 December 2020

Keywords:
Fear of Missing Out
FoMO
FoMO in the Workplace
Employees
Scale Adaptation

ÖZ

İşyerinde Gelişmeleri Kaçırma Korkusu, çalışanların işten uzakta veya işten ayrıldığında işle ilgili değerli firsatları kaçırabileceği endişesi olarak ifade edilebilir. Bu çalışmanın amacı, İşyerinde Gelişmeleri Kaçırma Korkusu Ölçeği'ni (Budnick, Rogers ve Barber, 2020) Türkçeye geçerlik ve güvenirliğini sağlayarak uyarlamaktır. Anket yöntemiyle 217 katılımcıdan toplanan veriler kullanılarak analizler yapılmıştır. Açımlayıcı faktör analizi sonucunda, 10 madde ve iki boyuttan (Bilgisel ve İlişkisel Dışlanma) oluşan bir ölçme aracı bulunmuştur. Doğrulayıcı faktör analizi sonucunda 10 madde ve iki boyutu gösteren modelin indeks değerlerinin iyi uyuma sahip olduğu görülmüştür. Ölçeğin düzeltilmiş madde toplam korelasyonları istenen düzeyde bulunmuştur. Sonuç olarak, ölçeğin Türkçeye uyarlanmış yapısının güvenilir ve geçerliliği olan bir ölçme aracı olduğu düşünülmektedir. Türkçe literatürde daha önce uyarlanmamış olan işyerinde gelişmeleri kaçırma korkusu ölçeğine ilişkin maddeler çalışmada yer almaktadır.

\section{A B S T R A C T}

The purpose of this study Fear of Missing Out at the workplace can be expressed as a concern that employees may miss valuable business opportunities when they are away from work. The aim of this study is to adapt the Fear of Missing Out in the Workplace Scale (Budnick, Rogers ve Barber, 2020) to Turkish by ensuring its validity and reliability. With the survey method, analyzes were made using the data collected from 217 participants. As a result of exploratory factor analysis, a measurement tool consisting of 10 items and two dimensions (Information and Relational Exclusion) was also found. Confirmatory factor analysis showed that the model showing 10 items and two dimensions had good fit index values. Corrected item-total correlations of the scale were found at the desired level. As a result, the structure of the scale adapted to Turkish is considered to be a reliable and valid measurement tool. Items of the fear of missing out in the workplace scale, which has not been adapted in the Turkish literature before, are included in the study.

\section{Giriş}

Gençler günlerinin büyük bir bölümünü sosyal mecralarda gezinerek arkadaşlarının ve kendilerinin durumlarını güncellemekle geçirebilmektir. Bundan dolayı başkalarının ne yaptığını, ne paylaştığını ve sürekli bağlantıda olma durumu Gelişmeleri Kaçırma Korkusu'nu(GKK) ortaya çıkarabilmektedir. Yapılan çalışmalar GKK'nın gençler üzerinde olumsuz etkisinin olduğunu göstermiştir (Przybylski vd., 2013). Yaygın olarak kullanılan genel GKK ölçüsü (yani, Pryzbylski vd., 2013), teknoloji iletişimine özgü öğeleri (örneğin, güncelleme durumu) içermektedir. Bununla birlikte, mevcut önlemler arkadaşlıklarla ilgili durumlara veya genel olarak bağlamı olmayan bireylere odaklanmaktadır (Pryzbylski vd., 2013). Bu durum göz önüne alındığında çalışanlar bağlamında potansiyel olarak ödüllendirici iş etkileşimlerine aktarırken, her ne kadar eğlenceli olmasa da işyerinde GKK ortaya çıkmaktadır.

\footnotetext{
* Sorumlu yazar/Corresponding author

e-posta: seyhanozdemir@sdu.edu.tr
}

e-ISSN: 2149-4622. C 2013-2021 Muş Alparslan Üniversitesi. TÜBİTAK ULAKBİM DergiPark ev sahipliğinde. Her hakk1 saklıdır. 
Sosyal medya dünyasında, GKK iyi bilinen bir fenomendir, ancak işyerinde ise, GKK yeni bir kavramdır (Lavenda, 2016). Genel GKK'nın insanlar üzerindeki olumsuz etkisine ilişkin tahminler, bilim insanları bu yapının çalışan sağlığı ve örgütsel davranışla nasıl ilişkili olduğunu daha iyi anlamaya çalışmaktadırlar. İşyeri GKK'nın işle ilgili teknoloji kullanım davranışını nasıl etkileyebileceği ele almaktadır. İşyeri GKK önlemi, teknolojik bağlantıların kaçırılmasıyla sınırlı değildir. Örneğin, bazı kuruluşlar çalışanlara çalışma ortamı dışında sosyalleşme firsatları sunmaktadır (örneğin, futbol, kurumsal piknikler gibi). Benzer şekilde, çalışanlar genellikle iş gününün bitiminden sonra geçici toplantılar yapmaktadır (örneğin, iş arkadaşları dışarı çıktıktan sonra bir şeyler yemek ve içmek için buluşması gibi). Bu araştırmada kullanılan işyeri GKK ölçüsü, teknoloji kullanımına veya daha geleneksel işyeri toplantılarına bakılmaksızın, özellikle işyeri GKK seviyelerini yakalamak için uygundur (Budnick, Rogers \& Barber, 2020).

Indeed.com tarafından yapılan bir araştırmaya göre, 500'den fazla çalışanı tatilde ofisten uzaktayken meslektaşlarını, müşterilerini, projelerini ve etkinliklerini kaçırıp kaçırmadıkları hakkında çeşitli sorular sorulmuştur. Çoğu çalışan, çalıştıkları atmosfer nedeniyle GKK deneyimi yaşadığı görülmektedir. Çalışanlar tatilde işten ve iş arkadaşlarından uzaktayken GKK'yı (gelişmeleri kaçırma korkusu) yaşıyor mu? sorusuna ise ankete katılanların ortalama \%45'inin ofis dışındayken iş arkadaşlarını veya işlerinin bazı yönlerini kaçırdığını göstermektedir. İlişkili olarak, işverenler de elverişli yeni ofis ortamları oluşturarak çalışanların işle ilgili önemli bilgileri kaçırmamaları için çaba harcamaktadırlar. GKK anketinin sonuçları, çalışanların çoğunun işten gurur duyduklarını ve işlerinden zevk aldıklarını vurgulamaktadır. O kadar ki tatildeyken bile iş yerinde neyi kaçırdıklarını düşünmektedirler (Yando, 2020)

Son olarak, işyeri GKK'nın genel GKK, sosyal kaygı ve sosyal karşılaştırma yönelimi gibi benzer yapılarla örtüştüğü görülmektedir, ancak bunlardan farklı olduğu görülmektedir. İşyeri GKK'nın çalışanların örgütsel bağlılığı, işe katılımı ve işle ilgili teknoloji kullanımıyla ilgili olduğunu göstermektedir. $\mathrm{Bu}$ çalışmayla işyerindeki gelişmeleri kaçırma korkusunu ölçebilmek için bu uyarlama çalışması yapılmıştır.

\section{Kavramsal Çerçeve}

Son zamanlarda hızla yayılan fenomenlerden biri olan FoMO (Fear of Missing Out), dilimize "sosyal ortamlarda gelişmeleri kaçırma korkusu" olarak girmiştir. Sosyal medyadan gücünü alan bu fenomen, sürekli güncelleme ve izleme davranışı, tüm dünyada Gelişmeleri Kaçırma Korkusu (GKK) olarak adlandırılmıştır (Przybylski vd., 2013). GKK, insanların sosyal olarak dışlanma korkuları sonucu meydana gelmektedir (Blackwell, 2017). Yine GKK, sosyal medyayı yoğun bir şekilde kullanan bireylerde görülmektedir. Sosyal mecralarda bir durum güncellemesinden, paylaşılan bir gönderiden ve çeşitli deneyimlerden haberdar olmama durumunda ortaya çıkan bir sorundur (Eşitti, 2015).

Przybylski vd. (2013: 1841) göre GKK, "başkalarının kendisi yokken güzel bir deneyimi yaşayabileceğine dair endişe" olarak tanımlanmaktadır. Başka bir tanıma göre ise "heyecan verici ya da ilginç bir olayın şu anda başka bir yerde gerçekleşebileceği endișesi” olarak ifade edilmektedir (Oxford Sözlük, 2020). Bu endişe bireylerin sosyal medya üzerinden bir şeyler kaçırmamak için sürekli başkalarının yaptıklarıyla bağlantılı olmalarıyla sonuçlanmaktadır. Sosyal medyanın, bir gruba ait olma ihtiyacından doğan GKK'nın giderilmesinde önemli rolü vardır (Wiesner, 2017).

Alanyazında GKK genellikle Öz Belirleme Kuramına (SelfDetermination Theory) dayandırılmaktadır (Budnick, Rogers \& Barber, 2020). Öz Belirleme Kuramı'nın amacı, "bireylerin, grupların, toplumların sağlıklı bir şekilde gelişmesini sağlayan koşulları" belirlemektedir. Ayrıca büyüme, bütünleşme, iyi olma sürecinde etkin olan faktörleri açıkça ortaya koymaktır (Ryan \& Deci, 2000). Öz Belirleme Kuramı'na göre insanlar doğuştan gelişmeye eğilimli canlılardır. Ancak bu eğilim kendiliğinden ortaya çıkmamaktadır, sosyal çevrenin desteğiyle meydana gelmektedir. Bundan dolayı, insanların faaliyetleri sosyal bağlam tarafından hem kolaylaştırılmakta, hem de zorlaştırılmaktadır. Bu bağlamda canlı organizma ile sosyal bağlam arasındaki etkileşim, Öz Belirleme Kuramı'nın davranış, deneyim ve gelişimiyle ilgili yordamalarına temel oluşturmaktadır (Kart \& Güldü, 2008). Kuram, kişilerin etkileşim ve sosyal ilişkiler sürecinde karşılaştığı tutum ve davranışları benimseyebilmektedir. Ayrıca, bu tutum ve davranışları içselleştirebildiğini de savunmaktadır (Grolnick, Deci \& Ryan, 1997). İlişkili olma ihtiyacı insanların başkaları ile bağlantılı olma ihtiyacıdır. İnsanların içinde bulunduğu sosyal çevrede ait olma duygusunu yaşaması ve insanlara özen göstermesidir (Kowal \& Fortier, 1999). İlişkiler, Öz Belirleme Kuramına göre ait olma ihtiyacını karşılamaktadır (Budnick, Rogers \& Barber, 2020).

Öz Belirleme Kuramı'na uygun olarak, eksiklikten korkan bireyler, işyeri sınırlarını bulanıklaştırmak ve sosyal bağlantı ihtiyaçlarını karşılamak için çalışmaya saatler sonra başlamak isteyebilmektedir (Budnick, Rogers \& Barber, 2020). İşyeri GKK, çalışanları iş iletişimine ve iş görevlerine bağlı kalmaya motive edebilecek bireysel bir farkı temsil etmektedir. İşyeri GKK'nın, eksik kaynak kazanma firsatları (yani kariyer gelişimi, bilgi veya karar verme sürecine girmesi) konusundaki endişeyi temsil ettiği göz önüne alındığında, yüksek işyeri GKK seviyeleri, psikolojik ihtiyaçların karşılanması arayışıyla olası kaynak kaybını önlemek için çalışma ortamına sık sık bağlanmayı motive etmelidir. Bu tür bir bağlantı, işle ilgili özel iletişim davranışı veya genel iş katılımı şeklinde olabilir. Yani burada ise, özellikle Öz Belirleme Kuramıyla ilişkilidir (Schaufeli \& Bakker, 2004). Öz Belirleme Kuramına uygun olarak, kaçırmaktan korkan bireyler, sosyal ilişki ihtiyaçlarını karşılamak için iş-ev sınırlarını bulanıklaştırmak ve saatler sonra işle meşgul olmak isteyebilmektedir. Bu tür çalışanlar aynı zamanda iş-ev sınırlarını belirlemek için daha az norm algıladıklarında, bu işe karşı daha olumlu tavırlar öngörebilir çünkü çalışanlar iş-ev sınırlarının bulanıklaşmasının işyeri kültürünün kabul edilebilir bir parçası olduğunu düşünmektedir (Budnick, Rogers \& Barber, 2020).

İşyerinde GKK, diğer çalışanlara göre, işten uzakta veya işten ayrıldığında değerli kariyer firsatlarını kaçırabileceğine dair yaygın bir endişe olarak tanımlanmaktadır. İşyerinde GKK, profesyonel ilişkiler kurma, değerli bilgiler edinme ve önemli kurumsal kararlara ve projelere katkıda bulunma gibi 
deneyimleri ödüllendirmede firsatları kaçırmak korkusu olarak ortaya çıkmaktadır. Örgütsel bağlamda, işyeri GKK'sının birbiriyle ilişkili iki tür bileşenden oluşmaktadır. Birincisi, ilişkisel dışlanma çalışanların ağ oluşturma fırsatlarının veya iş ilişkilerini sürdürme fırsatlarından dolayı profesyonel ilişkilerin kötüye gidebileceğine dair korkularını açıklamaktadır. İkincisi ise, bilgisel dışlanma, çalışanların bir gruptaki ilgili sosyal bilgilerden veya görev bilgilerinden haberdar olmama korkusuyla ilgilidir. Yani, döngü dışında kalma korkusudur (Budnick, Rogers \& Barber, 2020).

İşyerinde GKK'nın ana nedenlerinden biri, çalışanların gün boyunca düzenli olarak aldığı bildirim akışından ve önemli görevlerin kaçırılması ve firsatların kaybolması korkusundan kaynaklanmaktadır. Örgütler, çalışanların önemli bilgileri kaçırmamalarını sağlamanın yollarını aramaktadırlar. Yeni yazılımlar veya yeni uygulamalar kullanarak işyerlerindeki önemli bilgileri çalışanlara aktarmaktadırlar (Lavenda, 2016; Lozano, 2016). Çalışanlar iş yerinde, e-postalar, belgeler ve iş uygulamaları arasında geçiş yapmaktadır. Böylece patronlarından, iş arkadaşlarından veya müşterilerinden hiçbir şeyi kaçırmamayı istemektedirler. Yine çalışanlar telefonları veya bilgisayarları yeni güncellemeler için sürekli kontrol etmektedirler, çünkü önemli bir şeyi kaçırabileceklerinden korkmaktadır (Budnick, Rogers \& Barber, 2020). GKK, potansiyel olarak çalışanların kendi önceliklerine odaklanmak yerine iş arkadaşlarının katıldığı projelere dikkatini dağıtmasına neden olabilmektedir. Böylece bazı çalışanların farklı bir departmanın parçası olmalarını istemelerinden dolayı mevcut pozisyonlarından kendilerini ayr1 hissetmelerine neden olabilmektedir (Lavenda, 2016).

GKK hemen hemen her organizasyonda kaçınılmazdır. Olumsuz olarak GKK işyerlerinde strese neden olmaktadır (Lozano, 2016). Olumlu olarak ise, çalışanların kendilerini meşgul hissetmelerine yardımcı olur ve bu da çalışanların üretkenliğini artırmak için bir araç görevi görmelerini sağlamaktadır (Lavenda, 2016).

Literatürde Gelişmeleri Kaçırma Korkusu'na (FoMO) yönelik ölçekler bulunmaktadır; Genel Gelişmeleri Kaçırma Korkusu (FoMO) Ölçeği Przybylski vd. (2013) tarafından geliştirilmiş, Gökler vd. (2016) tarafindan Türkçeye uyarlanmıştır. Yapılan araştırmalarda GKK sosyal ağların kullanımdaki artışın arkasındaki itici güç olarak bulunmuştur. Ayrıca GKK gençlerde daha yüksek bulunmakta ve yaşam memnuniyet düzeyini düşürdüğü sonucuna varılmıştır.

Genel Gelişmeleri Kaçırma Korkusuna (FoMO) yönelik başka bir ölçek ise Wegmann vd. (2017) tarafindan Przybylski vd. (2013) geliştirmiş olduğu ölçeğin güncellenmiş ve geliştirilmiş halidir. Balta vd. (2018) tarafından Türkçeye uyarlanmıştır. GKK ile ilgili geliştirilen ölçekler daha çok genç bireylerin GKK düzeylerini ölçmeye yöneliktir. Ancak bu uyarlanan ölçek ise işyerlerine yönelik gelişmeleri kaçırma korkusunu ölçmeye yöneliktir. GGK işyeri hakkında ulusal yazında bugüne kadar herhangi bir araştırma bulunmamaktadır. Genel GKK ölçekleri iş bağlamında çalışan yetişkinler için uygun değildir.

İş dışı bağlamında GKK yaygın bir fenomendir (Milyavskaya vd., 2018). Özellikle Y kuşağında GKK sadece kültürel bir fenomen değil, bir salgın haline gelmiştir (Taylor, 2014). Y kuşağın iş ortamına girmesiyle birlikte artık çalıșma ortamında da GKK'ya rastlamak mümkün olabilmektedir. Bu sebeple ölçeğin Türkçeye uyarlamasına ihtiyaç duyulmuştur. Türkçe alan yazındaki bu boşluğu doldurup, araştırmacılara faydalı olacak bir ölçek kazandırmak amacıyla bu ölçek uyarlaması yapılmıștır. Ulusal alandaki boşluğun Budnick, Rogers ve Barber (2020) tarafından geliştirilen İşyerinde GKK ölçeği ile dolduracağı düşünülmektedir. Ayrıca işyerinde GKK, örgütsel bağlamda çalışanlar arasında daha fazla araştırmayı hak eden, potansiyel olarak yaygın bir olgudur.

\section{Yöntem ve Uygulama}

Bu başlıkta katılımcılar, ölçüm araçları ve çeviri işlemleri verilmiştir.

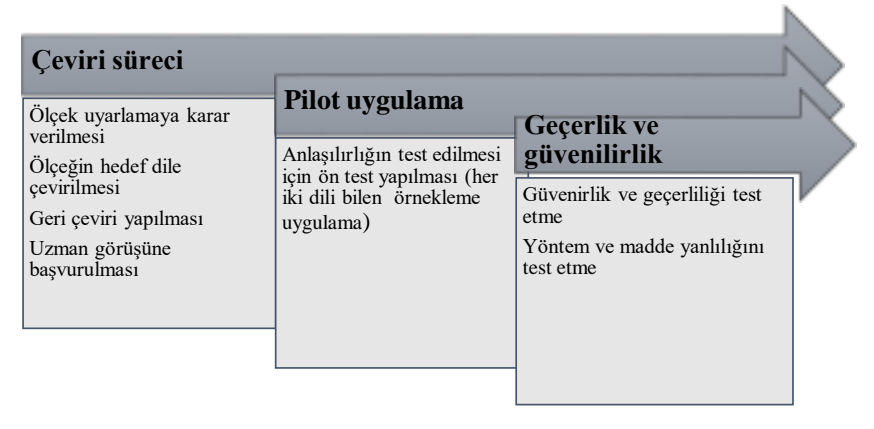

Şekil 1. Ölçek Uyarlama Süreci

Şekil 1'deki süreç izlenmiştir. İlk aşamada çeviri, ikinci aşamada pilot uygulama ve üçüncüsü aşamada ise geçerlik ve güvenilirlik süreçleri takip edilmiştir.

\subsection{Kat1limcilar}

Araştırmanın katılımcıları farklı sektörlerde(eğitim, hizmet, teknoloji, tekstil, sağlık) çalışan yaşları 22 ile 60 arasında değişen (Ort.yaş=30.74, SS $_{\text {yaş }}=6.961$ ), \%64.4 erkek, \%39.6 kadın toplam 217 kişiden oluşmaktadır. Katılımcılar, kolayda örneklem yöntemiyle araştırmaya gönüllü olarak katılmışlardır. Cep telefonlarının yaygın kullanımı ve birçok sektörde ve iş türünde GKK olası yaygınlığı öngörülerek kolayda örneklemle geniş bir örneklem seçilmiştir. Katılımcıların \%52.5'i evli iken, \%47.5'i evli değildir. Katılımcılar eğitim düzeylerine göre bakıldığında \%7.8'i lise, \%10.1'i önlisans, \%49.8'i lisans ve \%32.3'ü lisansüstü eğitim seviyelerine sahiptir. Son olarak katılımcıların ortalama mesleki tecrübeleri ise 2 ile 50 yıl arasında $\left(\right.$ Ort.tecrübe $\left.=6.85, \mathrm{SS}_{\text {.tecrübe }}=6.71\right)$ değişmektedir. Etik izinler (Ek-1) Süleyman Demirel Üniversitesi Etik Kurulu'ndan alınmıştır (ref. 87432956/050.99/56739).

\section{2. Ölçüm Araçları}

Genel GKK Ölçeği(GGKK): Wegmann vd. (2017)'de geliştirdiği ölçek, Balta vd. (2018) tarafindan Türkçeye uyarlanmıştır. FoMO, sosyal medya üzerinde gelişmeleri kaçırma korkusunu belirlemeyi amaçlayan bir ölçektir. Ölçek 12 maddeden oluşmaktadır ve iki boyutludur. Ölçek 5'li Likert (1= Hiçbir Zaman, 5= Her Zaman) şekildedir. Örnek madde "Arkadaşlarımın benimkilerden daha doyurucu deneyimler yaşadığından korkarım." ve "Hiçbir şey kaçırmamak için sürekli çevrimiçi olurum." şeklinde verilebilir. 
Genel GKK Ölçeği yakınsak geçerliliği sağlamak amacıyla kullanılmıștır. Teorik olarak ilişkili yapıların kullanılması ve gerçekte de ilişkili bulunması yakınsak geçerliliğin ortaya konulmasını sağlamaktadır.

İsyerinde GKK Ölçeği: Bu çalışmada, Budnick, Rogers ve Barber (2020) tarafindan geliştirilen İşyerinde Gelişmeleri Kaçırma Korkusu Ölçeğini Türkçeye uyarlamaktır. Ölçek iki boyuttan (Bilgisel Dişlanma (5) ve İlişkisel Dişlanma (5)) oluşan toplam 10 maddelik bir ölçüm aracıdır. Ölçekte ters madde bulunmamaktadır. Ölçek 5'li Likert (1= Kesinlikle katılmıyorum, 5= Kesinlikle katılıyorum) şekildedir. Özgün çalışmada boyutların iç tutarlılık değerleri Bilgisel Dışlanma $(\alpha=0.91)$ ve İlişkisel Dişlanma $(\alpha=0.91)$ olarak verilmiştir.

Anketle toplanan veriler tek kaynaktan toplandığ 1 için Harman'ın tek faktör testini kullanarak ortak yöntem yanlılığını test etmeye ihtiyaç vardır. Ortak yöntem varyansını (common method variance) test etmek için öncelikle Harman'ın tek-faktör (single-factor) testi uygulanmıştır (Podsakoff vd., 2003). Tek faktörde açıklanan varyans miktarı \%36,3'tür. Tek faktörde açıklanan varyans değerin \%50'nin altında olması gerektiğini belirtmiştir (Kline, 2015). Bu çalışmada ölçülen değer \%50'nin altında olduğu bulunmuştur. Böylece ortak yöntem hatası olmadığı sonucuna varılmıştır.

Katılımcıların sosyal istenirliklerini, yanlılık ve cevaplama tercihlerini etkileyebilecek süreçlerin tespit edilmesi için ortak gizil faktörlü model (common latent factor) test edilmiştir. Özellikle kültürlerarası çalışmaların ölçüm denkliği konusunda ele alınması önerilmektedir (Lilleoja, Dobewall, Aavik, Strack, \& Verkasalo, 2016). Bu modeli ölçmek için tek bir ortak faktöre dâhil edilir ve diğer bütün gizil faktörlerin maddelerine yüklendirilir. Ancak diğer gizil faktörler ile ortak gizil faktörler arasında korelasyona izin verilmez (Chen vd., 2006). Gösterilen tüm değişkenler için ortak gizil faktörlü değeri $=0.147$ ve $p=0.001$ değerlerinin anlamlı olduğu bulunmuştur(Ek-2, Şekil 4). Ortak yöntem varyansı, bu değerin karesidir, $0.147^{2}=0.0216$. Bu nedenle, Ortak Gizil Faktör tekniği, hesaplanan varyans (\%021) \%50 eşiğinin altında olduğu için bu verilerde önemli bir ortak yöntem yanlılığı olmadığını göstermektedir (Eichhorn, 2014).

\section{3. İşlem ve Veri Analizi}

İzin alınması: Ölçeğin Türkçe'ye uyarlanması için sorumlu yazar olan Christopher J. Budnick (2020) tarafindan mail yoluyla gerekli izin alınmıştır.

Çeviri ve kültürel eşdeğerlik çalışmast: İşyerinde Gelişmeleri Kaçırma Korkusu Ölçeği Türkçe uyarlama çalışmasında öncelikle "ölçeğin çevirisi için ilk çeviri, ilk çeviriyi değerlendirme, geri çeviri, geri çeviriyi değerlendirme ve uzman görüşüne sunma biçiminde beş aşamadan oluşan bir model temel alınmıştır" (Brislin vd., 1973a; 1973b). Ölçme aracı, iki dile (İngilizce ve Türkçe) hâkim olan üç akademisyen tarafından Türkçeye çevrilmiştir. Tercüme edilen ölçek, GKK ile ilgili çalışması olan 4 akademisyene gönderilmiş ve ölçeğin anlaşılırlığı, bağlama uyumlu olup olmadı̆̆ı ve yapısı bakımından incelenmiştir. Türkçeye çevrilen ölçek ifadeleri farklı kurumda çalışan 3 akademisyen tarafından İngilizceye geri çevrilmiştir Buradaki amaç, Türkçe ve İngilizce ölçme araçları arasındaki tutarlılığın incelenmesidir. Ölçek paralel kör teknik kullanılarak (Brislin, 1980) Türkçeye çevrildikten sonra ön uygulamaya geçilmiştir. Süreç, ölçeğin hedef dile çevrilmesi (Forward), uzman görüşlerinin alınması, ölçeğin hedef dilden orijinal dile çevrilmesi ve uyarlanmış ölçeğe son halinin verilmesi şeklinde yapılmıştır.

Ön uygulama: Ölçek, hedeflenen gruba uygulanmadan önce ölçek ifadeleri hem İngilizce hem de Türkçeleriyle beraber 9 araştırma görevlisine uygulanmıştır. Öğretim elemanlarının geri dönüşleri sonrasında ölçek ifadelerinin anlaşılır olup olmadığı değerlendirilmiştir. Ölçüm aracına son hali verilmiştir.

Uygulama ve psikometrik analizler: Son aşamada veriler üzerinde ölçeğin özgün iki boyutlu yapısı, doğrulayıcı faktör analiziyle test edilmiştir. Ölçeğin güvenirliği $C R$ ve Cronbach Alfa değerleriyle, madde analiziyle de düzeltilmiş madde-toplam korelâsyonu elde edilmiştir. Geçerlik ve güvenilirlik analizlerinde, IBM SPSS 25 ve AMOS 24 programlarından faydalanılmıştır.

\section{Bulgular}

$\mathrm{Bu}$ başlık altında ise Türkçe'ye uyarlanması amaçlanan ölçeğin geçerlilik ve güvenilirliği araştırılmıştır. Analiz sonuçları aşağıdaki verilmiştir.

\subsection{Geçerlilik Analizleri}

Ölçeğin yapı yanlılığını test için AFA (Açımlayıcı Faktör Analizi) ve DFA (Doğrulayıcı Faktör Analizi) uygulanmıştır. KMO testi örneklem yeterliliğini(ilişki) göstermektedir (Can, 2017). Bu çalışmada KMO (KaiserMeyer-Olkin) değeri test edilmiştir. Analiz neticesinde KMO değeri 0.90 ve $(p<.000)$ anlamlı olarak bulunmuştur. Bartlett küresellik testinin anlamlı çıkması (0.05) verilerin faktör analizi için uygun olduğunu göstermektedir. Verilerin faktör analizine uygun olduğu saptanmıştır. Faktörleri yorumlama kolaylığından dolayı en çok tercih edilen varimax döndürme tekniği kullanılmıştır (Gürbüz \& Şahin, 2014).

Anti-İmaj Korelasyon Matrisi, "her maddenin faktör çözümlemesi içinde kalıp kalmamasına karar verilmesi için bir ölçüt" sunmaktadır (Can, 2017). Maddelerin kesişim noktasındaki değerlerin 0.5 'in üzerinde olması beklenmektedir. Bu çalışmada ise, 0.884 ile 0.954 değerleri arasında bulunmuştur. Tablo 1'de AFA ile ulaşılan sonuçlara, ortalamalara ve standart sapmalara yer verilmiştir. 
Tablo 1. İşyerinde GKK Ölçeği AFA Sonuçları

\begin{tabular}{|c|c|c|c|}
\hline Ölçek İfadeleri & $\begin{array}{l}\text { Faktör } \\
\text { Yükü }\end{array}$ & Ort & S.S. \\
\hline s1.İşyerinde bulunmadığımda, işle ilgili önemli gelişmeleri kaçırabileceğimden endişe ederim. & .904 & 3.48 & 1.302 \\
\hline s2.İşyerinde bulunmadığımda, işle ilgili değerli bilgileri kaçırabileceğim için endişe ederim. & .811 & 3.57 & 1.304 \\
\hline s3.İsyerinde bulunmadığımda, işle ilgili önemli haberleri kaçıracağımdan endişe ederim. & .821 & 3.31 & 1.338 \\
\hline s4.İşyerinde bulunmadığımda, işimle ilgili önemli bilgileri kaçıracağımdan endişe ederim. & .848 & 3.51 & 1.316 \\
\hline s5.İşyerinde bulunmadığımda, iş’te neler olduğunu bilmeyeceğimden endişe ederim. & .577 & 3.17 & 1.355 \\
\hline $\begin{array}{l}\text { s6.İ̌syerinde bulunmadığımda, önemli iş bağlantıları kurma firsatını kaçıracağım konusunda } \\
\text { endişe ederim. }\end{array}$ & .807 & 3.00 & 1.429 \\
\hline $\begin{array}{l}\text { s7.İşyerinde bulunmadığımda, sürekli iş bağlantılarını güçlendirme fırsatlarını kaçırabileceğimi } \\
\text { düşünürm. }\end{array}$ & .825 & 2.93 & 1.401 \\
\hline $\begin{array}{l}\text { s8. İşyerinde bulunmadığımda, sürekli yeni iş bağlantıları kurma firsatlarını kaçırabileceğimi } \\
\text { düşünürüm. }\end{array}$ & .813 & 2.90 & 1.381 \\
\hline $\begin{array}{l}\text { s9.İşyerinde bulunmadığımda, iş arkadaşlarımın sahip olacağı ağ(network) firsatlarını } \\
\text { kaçıracağımdan endișe ederim. }\end{array}$ & .829 & 2.68 & 1.393 \\
\hline $\begin{array}{l}\text { s10.İsyerinde bulunmadığımda, iş arkadaşlarımın benim kuramayacağım iş bağlantıları } \\
\text { kurabileceğinden korkarım. }\end{array}$ & .757 & 2.39 & 1.430 \\
\hline 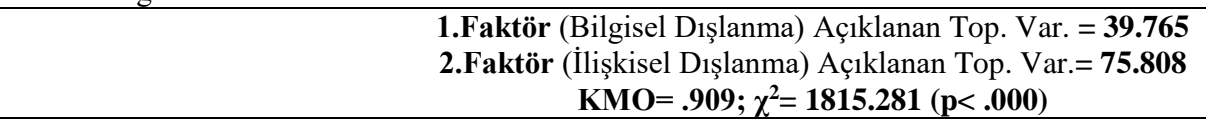 & & & \\
\hline
\end{tabular}

Tablo 1 incelendiğinde AFA sonucunda orijinal ölçekteki ile benzerlik gösteren iki boyutlu faktör yapıs1 ortaya çıkmıştır. Birinci boyut Bilgisel Dışlanma (s1, s2, s3, s4, s5) ikinci boyut ise, İlişkisel Dişlanmadır (s6, s7, s8, s9, s10) Maddelerin faktör yükleri incelendiğinde 0.577 ile 0.904 arasında değerler aldığı görülmektedir. Ayrıca maddelerin aritmetik ortalama değerlerine bakıldığında 2.39 ile 3.57 arasında puanlar almıştır.
Özdeğeri 1'den büyük olan iki bileșenle iki boyut belirlenmiştir (Can, 2017). Bunlar toplam varyansın \%75.808'ini açıklamaktadır. Faktör analizi sonucunda orijinal ölçme aracının boyutlarıyla aynı olduğu görülmüştür. Şekil 2'de Çizgi Grafiği iki boyutlu yapıyı ifade etmektedir.

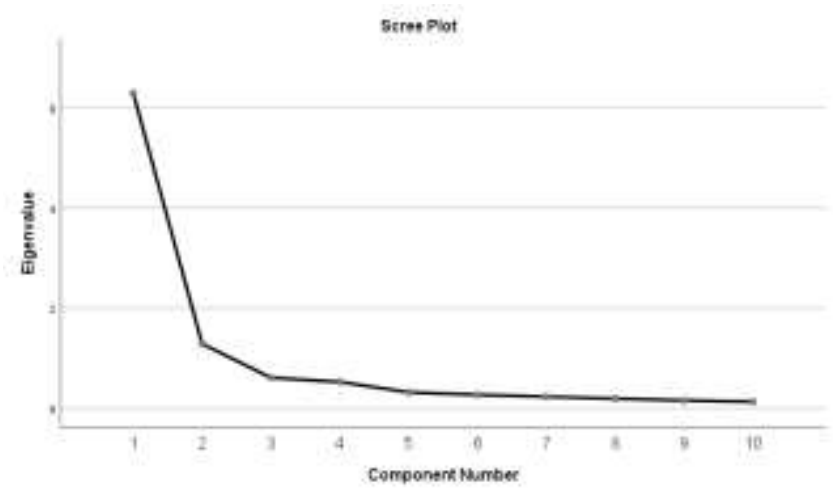

Şekil 2. Çizgi Grafiği

"Bir ölçeği DFA ile doğrulaması, o ölçeğin geçerli bir ölçek olduğuna işaret" etmektedir (Gürbüz \& Şahin, 2014). Yapı geçerliliği için doğrulayıcı faktör analizi uygulanmıştır. Yapısı bilinen ya da daha önce kullanılmış ölçekler kullanılması durumunda DFA yapılmaktadır. DFA ölçeğin öngörülen kuramsal yapısını doğrulamaya çalışmaktadır.
DFA birinci düzey tek faktörlü model ve ikinci düzey çok faktörlü model olarak ele alınmaktadır. İkinci düzey DFA çok faktörlü ölçekleri doğrulamak için kullanılmaktadır (Gürbüz, 2019). DFA'dan elde edilen uyum iyiliği değerleri Tablo 2'de verilmiştir.

Tablo 2. Ölçeğin Uyum İyiliği Değerleri

\begin{tabular}{lccccccc}
\hline \multicolumn{1}{c}{ Ölçek Adı } & İfade Sayısı & $\boldsymbol{\chi 2} / \boldsymbol{d} \boldsymbol{f}$ & CFI & TFI & GFI & SRMR & RMSEA \\
\hline Birinci Düzey İki Faktörlü DFA & 10 & 2.09 & .98 & .97 & .94 & .04 & .06 \\
İkinci Düzey Tek Faktörlü DFA & 10 & 3.16 & .96 & .94 & .92 & .05 & .08 \\
\hline Kabul edilebilir uyum* & & $\leq 5$ & $>0.90$ & $>0.90$ & $>0.85$ & $<0.08$ & $<0.08$ \\
İyi uyum * & $\leq 3$ & $>0.97$ & $>0.95$ & $>0.90$ & $<0.05$ & $<0.05$ \\
\hline *Joreskog ve Sorbom, (1993); Kline, (1998) & & & & & &
\end{tabular}


Tablo 2 görüldüğü üzere, Maximum Likelihood yöntemi kullanılarak ölçeklerin öngörülen yapılarının, toplanan veri ile desteklenip desteklenmediği alternatifli modellerle test edilmiştir (Gürbüz, 2019). Öngörülen iki boyutlu modelin (İki boyutlu Bilgisel ve İlişkisel, tek boyutlu İşyerinde GKK) $\chi^{2}$ farklılık testleri kullanılarak iki farklı alternatif model karşıllaştırılmıştır.

Birinci düzey iki faktörlü yapı en iyi uyum sağlayan model olarak saptanmıştır. Bu bulgulardan yola çıkarak ölçeğin ayrışım geçerliliğine sahip olduğu söylenebilir. Ölçeklerle ilgili uyum değerleri kabul edilebilir ve iyi uyum indeksleri değer aralığında olduğu bulunmuştur (Jöreskog \& Sörbom, 1993; Kline, 1998).

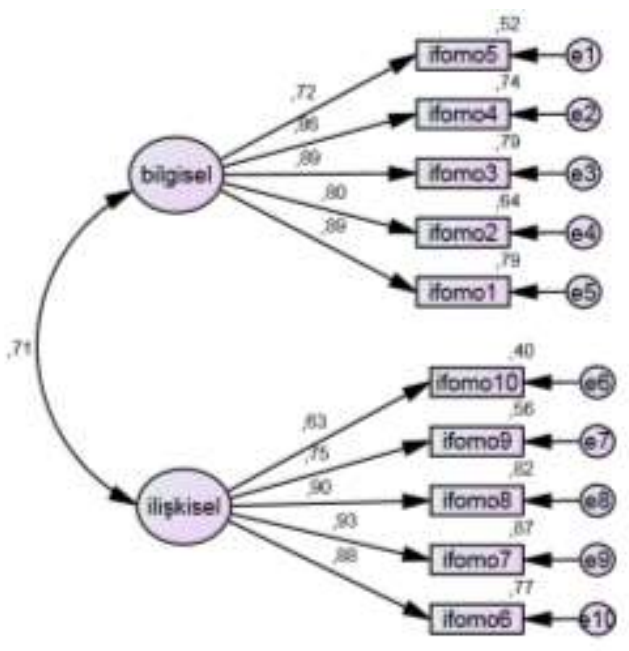

Şekil 3. DFA Sonuçları
Şekil 3 incelendiğinde birinci düzey DFA sonuçları iki faktörlü DFA modeli, bir ölçeğin iki boyutlu olduğu anlamına gelmektedir. Faktör yüklerine bakıldığında 0.63 ile 0.93 arasında olduğu görülmektedir. Tablo 3 'te standardize regresyon ağırlıkları verilmiştir.

Tablo 3. Standardize Regresyon Ağırlıkları

\begin{tabular}{|c|c|c|c|}
\hline İfadeler & & & Tahmin değerleri \\
\hline ifomo5 & $\leftarrow$ & Bilgisel &, 724 \\
\hline ifomo4 & $\leftarrow$ & Bilgisel & ,859 \\
\hline ifomo3 & $\leftarrow$ & Bilgisel & , 891 \\
\hline ifomo2 & $\leftarrow$ & Bilgisel & ,797 \\
\hline ifomo1 & $\leftarrow$ & Bilgisel & ,890 \\
\hline ifomo10 & $\leftarrow$ & İlişkisel & 631 \\
\hline ifomo9 & $\leftarrow$ & İlişkisel & ,752 \\
\hline ifomo8 & $\leftarrow$ & İlişkisel & ,905 \\
\hline ifomo7 & $\leftarrow$ & İlişkisel & 931 \\
\hline ifomo6 & $\leftarrow$ & İlişkisel &, 880 \\
\hline
\end{tabular}

Ölçüm modelinin faktörler arası korelasyon ve AVE, CR, MSV ve $\operatorname{MaxR}(\mathrm{H})$ değerleri Tablo 4'te verilmiştir.

Tablo 4. Faktörler Arası Korelasyon, AVE, CR, MSV ve MaxR(H) Değerleri

\begin{tabular}{cccccccc}
\hline Faktörler & CR & AVE & MSV & MaxR(H) & 1 & $\mathbf{2}$ & $\mathbf{3}$ \\
\hline 1.Bilgisel Dışlanma & 0.928 & 0.687 & 0.504 & 0.930 & $\mathbf{( 0 . 8 3 5 )}$ & & \\
2.İliş̧kisel Dışlanma & 0.914 & 0.684 & 0.539 & 0.944 & $.710^{* *}$ & $\mathbf{( 0 . 8 2 7 )}$ & \\
\hline
\end{tabular}

Not: CR (Composite reliability-Birleşik/yapı güvenirliği), AVE (Average variance extracted- Ortalama açıklanan varyans), MSV (Maximum squared varience-Maksimum paylaşılan varyansın karesi), MaxR(H)(Maximum reliability-Maksimum güvenilirlik), Parentez içindeki değerler $\sqrt{ }$ AVE değerlerini göstermektedir.

İşyerinde GKK ölçeğine ait boyutların güvenirliği için CR tercih edilmiștir. CR'nin içsel tutarlılık katsayısı Cronbach Alfadan daha iyi bir alternatif model olduğu kabul edilmektedir (Kline, 2015). Birleşim ve ayrışım geçerliliği için ise AVE, MSV ve MaxR(H) değerleri hesaplanmıştır. Birleşim geçerliliği için $\mathrm{CR}>$.7; AVE >.5; CR>AVE olması, ayrışım geçerliliği için ise AVE $>M S V$, $\sqrt{ }$ AVE $>$ faktörler arası korelasyon olması önerilmektedir (Hair vd., 2014; Hu \& Bentler, 1999). Yapılan analiz sonucunda $\sqrt{ }$ AVE değerleri faktörler aras1 korelasyondan $(\mathrm{r}=.710)$ büyük olduğu bulunmuştur. Ayrica CR değerlerinin AVE değerinden büyük olduğu ve AVE değerinin 0.5 'den büyük olduğu bulunmuştur. Sonuç olarak ölçeğin orijinal faktör yapısının korunduğu ve Türk kültüründe de geçerli olduğu sonucu saplanılmıştır.
Tablo 5. İGKK Ölçeğinin Yakınsak Kavramlarla Olan Korelasyonlar1

\begin{tabular}{llrrrr}
\hline Ölçekler & Faktörler & \multicolumn{1}{c}{ Bilgisel } & İlişkisel & Kișisel & Durum \\
\hline İGKK & Bilgisel & 1 & & & \\
& İlişkisel &, $681^{* *}$ & 1 & & \\
\multirow{2}{*}{ GGKK } & Kişisel &, $365^{* *}$ &, $400^{* *}$ & 1 & \\
& Durum &, $292^{* *}$ &, $336^{* *}$ &, $611^{* *}$ & 1 \\
\hline ** Korelasyon $p \leq 01$ seviyesinde anlamlıdır & &
\end{tabular}

Ölçeğin boyutlarının yakınsak kavramlarla ilișkilerinin geçerliliğini göstermektedir. Tablo 5'te İGKK ölçeğinin yakınsak kavramlarla olan korelasyonuna bakılmıştır. Boyutlar arasındaki ilişki korelasyonları pozitif yönde ve anlamlıdır.

\subsection{Güvenilirlik Analizleri}

$\mathrm{Bu}$ başlık altında tanımlayıcı istatistikler ve değişkenler arasındaki ilişkiler ele alınmıştır. 
Tablo 6. Tanımlayıcı İstatistikler ve Değişkenler Arasındaki İlişkiler

\begin{tabular}{lcccccccc}
\hline Değişkenler $(\mathbf{N}=\mathbf{2 1 7})$ & $\overline{\mathbf{x}}$ & $\mathbf{S S}$ & Çarp. & Basık. & $\mathbf{1}$ & $\mathbf{2}$ & $\mathbf{3}$ & $\mathbf{4}$ \\
\hline 1.Yaş & 30.74 & 6.961 & - & - & - & & & \\
2.Cinsiyet & 1.40 & 0.490 & - & - & $-.177^{* * *}$ & - & & \\
3.Bilgisel Dışlanma & 3.40 & 1.144 & -.392 & -.701 & $-.211^{* *}$ & .005 & $(.91)$ & \\
4.İlişkisel Dıșlanma & 2.77 & 1.212 & .278 & -.960 & $-.260^{* *}$ & .024 & $.710^{* *}$ & $(.91)$ \\
\hline
\end{tabular}

Not: Parantez içindeki değerler ölçeklerin Cronbach Alfa değerleridir.

Çalışma verileri normal dağılım göstermektedir. Çarpıklık ve basıklık katsayıları \pm 1 aralığında gözlenmektedir. $\mathrm{Bu}$ durum, verilerin normal dağılım gösterdiği şeklinde ifade edilebilir (Morgan vd., 2004). Tablo 6'da değişkenlere ait ortalama değerler gösterilmiştir. Verilen tabloda çalışanların işyerinde gelişmeleri kaçırma korkusu ortalaması $(3.09 \pm 1.080)$ iken, genel gelişmeleri kaçırma korkusu ortalaması (2.40 \pm 0.857$)$ olarak bulunmuştur. Boyutlar arasında pozitif yönlü anlamlı ilişki olduğu sonucuna varılmıştır. Cinsiyet değişkeni ile diğer değişkenler arasında ise ilişki bulunamamıştır.

Tablo 7. Ölçeğe İlişkin Güvenilirlik Sonuçları ve Madde Analizi

\begin{tabular}{cccccc}
\hline Madde No & Çarp. & Bask. & $\begin{array}{c}\text { Düzeltilmiş Madde- } \\
\text { Toplam Korelasyonu }\end{array}$ & $\begin{array}{c}\text { Özgün Ölçek } \\
(\boldsymbol{\alpha})\end{array}$ & $\begin{array}{c}\text { Türkçe Form } \\
(\boldsymbol{\alpha})\end{array}$ \\
\hline 1. İGKK & -.462 & -.845 & .722 & & \\
2. İGKK & -.559 & -.837 & .697 & & \\
3. İGKK & -.320 & -1.100 & .782 & & \\
4. İGKK & -.556 & -.827 & .742 & $\mathbf{. 9 4}$ & \\
5. İGKK & -.178 & -1.159 & .731 & \\
6. İGKK & .066 & -1.277 & .790 & $\mathbf{9 3}$ \\
7. İGKK & .083 & -1.270 & .821 & \\
8. İGKK & .098 & -1.246 & .781 & \\
9. İGKK & .303 & -1.169 & .701 & \\
10. İGKK & .647 & -.953 & .605 & & \\
\hline Not: IGKK (Işyerinde $G K K)$ &
\end{tabular}

Tablo 7 incelendiğinde, maddelerin çarpıklık ve basıklık değerleri verilmiştir. Çarpklık ve basıklık \pm 1.5 değerlerinde olduğunda normal dağılım olarak kabul edilmektedir (Tabachnick \& Fidell, 2013). Düzeltilmiş madde-toplam korelasyonları 0.605 ile 0.821 arasında değerler aldığı görülmektedir. "Ölçek maddelerinin düzeltilmiş maddetoplam korelasyonunun 0.30 'un üzerinde olması gerekliliği ve 0.30 ve üzeri olan maddelerin iyi maddeler olduğu belirtilmektedir" (Büyüköztürk, 2005; Can, 2017). Bu kapsamda ölçek maddelerinin ayırt etme yeterliliğine sahip olduğu söylenebilir. Ölçeğin iç tutarlılığına ilișkin güvenilirlik katsayısı 0.93 olarak bulunmuştur. Ölçeğin özgün iç tutarlılık değeri ise 0.94 'tür.

İşyerinde GKK ölçeğinin test-tekrar test güvenilirliği kapsamında araştırmaya katılan 47 kişiye anket uygulanmıştır. Test-tekrar test güvenilirlik katsayısı 0.94 olarak bulunmuştur.

\section{Sonuç}

$\mathrm{Bu}$ ölçek uyarlama çalışmasında, 10 maddelik iki boyutlu (Bilgisel ve İlişkisel Dışlanma) İşyerinde Gelişmeleri Kaçırma Korkusu Ölçeği'nin (İGKK) (Budnick, Rogers \& Barber, 2020) Türkiye bağlamında güvenilirlik ve geçerliliği incelenmiştir. Uyarlama çalışmasında Brislin vd. (1973a, 1973b) tarafindan önerilen süreç takip edilmiştir. Örneklem büyüklüğünün 200'ün üzerinde olması geçerlik ve güvenilirlik çalışmalarının yürütülmesi açısından yeterlidir (Gürbüz \& Şahin, 2014). Ölçeğin güvenilirliğini sınamak adına $C R$ katsayıları değerlendirildiğinde, boyutlar ve
İşyeri GKK'sının yaş ve cinsiyete göre farklılık gösterip göstermediğini test ettiğimizde, yaşa $(\mathrm{r}=-.257, \mathrm{p}=.000)$ göre anlamlı ilişki gözlenmiş ancak cinsiyete $(r=-.016, p=.81)$ göre anlamlı ilişki gözlenmemiştir. ANOVA test sonuçlarına göre yaş ortalaması artıkça işyerinde GKK seviyesi düşmektedir $(\mathrm{F}=5.23, \mathrm{p}=, 002)$. Bu bulgular daha önceki yapılan çalışmaların (Pryzbylski vd., 2013; Budnick, Rogers \& Barber, 2020) sonuçlarıyla paralellik göstermektedir. Güvenilirliğe ilişkin analizlerinden elde edilen bulgular Tablo 7'de verilmiştir. maddelerin orijinal formla uyum gösterdiği görülmektedir. $\mathrm{Bu}$ işlemler neticesinde orijinal formdan herhangi bir madde çıkarılmamıştır. Elde edilen değerler özgün ölçeğin değerleriyle paralellik göstermektedir (Budnick, Rogers \& Barber, 2020). Netice olarak, İGK, Türkçe formuyla geçerli ve güvenilir bir ölçme aracı sunmaktadır. Analiz neticeleri ölçme aracının kullanılabilir olduğunu göstermektedir. Diğer yandan, farklı mesleklerde çalışanlarından alınmış olması, farklı popülasyonlar ve alanlar üzerinde yapılacak ölçek uyarlama çalışmalarını önemli kılmaktadır.

Alanyazında genel GKK'ya yönelik iki uyarlama ölçek (Gökler vd., 2016; Balta vd., 2018) bulunmaktadır. Bu uyarlan ölçek ise iki ölçekten farklılaşmaktadır. Genel GKK ile ilgili geliştirilen ölçekler daha çok genç bireylerin GKK düzeylerini ölçmeye yöneliktir. Ayrıca ölçekler arkadaşlıklarla ilgili durumlara veya genel olarak bağlamı olmayan bireylere yönelik gelișmeleri kaçırmamaya odaklanmaktadır. Ancak bu ölçek ise işyerlerine yönelik gelişmeleri kaçırma korkusunu yöneliktir. Genel GKK ölçekleri iş bağlamında çalışan yetişkinler için uygun olmayabilir. Teknoloji araçlarında geçirilen sürenin her geçen gün artması işyerindeki gelişmeleri kaçırma korkusu çalışmaların önemini artırmaktadır. Ayrıca Y kuşağının iş hayatına atılmasıyla birlikte işyerinde de gelişmeleri kaçırma korkusunun ortaya çıkabileceği düşünülmektedir.

İş yaşamında teknolojinin giderek yaygınlaşması, genç nüfusun iş ortamında olması ve sosyal mecraların daha da 
yaygınlaşması GKK davranışını yaygınlaşmasına neden olabilir. Ölçeğin, sosyal ortamda gelişmeleri kaçırma korkusuna alternatif olarak, işyerinde gelişmeleri kaçırma korkusunu ölçüme imkân tanıması, araştırmacılar tarafından tercih edilme ihtimalini artırmaktadır. Ölçeğin bu alanda literatüre katkı sağlayacağı düşünülmektedir.

$\mathrm{Bu}$ çalışmanın, ortak yöntem varyansı hatasının olması, katılımcıların tek kültürden seçilmiş olması, kesitsel bir çalışma olması, sosyal istenirlik etkisinin olması, katılımcıların nesnel görüşlerine dayanması ve çalışma verileri anket kullanılarak toplanması gibi sınırlılıkları bulunmaktadır. Gelecekteki çalışmalarda, uyarlanan ölçeğin farklı değișkenlerle ilișkilerinin araștırılmasıyla elde edilecek bulgularla genellenebilir. Ayrıca, mutluluk, öznel iyi oluş, örgütsel destek, yöneticiye güven, örgüte bağlılık ve çalışan bağlılığı gibi örgütsel davranış değişkenleriyle çalışmalar yürütülebilir.

\section{Kaynakça}

Bakker, A. B., \& Demerouti, E. (2006). The job demandsresources model: State of the art. Journal of Managerial Psychology, 22, 309-328.

Balta, S., Emirtekin, E., Kircaburun, K., \& Griffiths, M. D. (2018). Neuroticism, trait fear of missing out, and phubbing: The mediating role of state fear of missing out and problematic Instagram use. International Journal of Mental Health and Addiction, 18, 628639.

Blackwell, David, Leaman, Carriel, Tramposch, Rose, Osborne, Ciera, \& Liss, Miriam (2017) Extraversion, Neuroticism, Attachment Style And Fear Of Missing Out As Predictors Of Social Media Use And Addiction, Personality And Individual Differences, 116, 69-72.

Brislin, R. W. (1980). Translation and content analysis of oral and written materials. In J. W. Berry \& H. C. Triandis (Eds.), Handbook of Cross-Cultural Psychology 2, 389-444.

Brislin, R. W., Lanner, W. J. ve Thorndike, R. M. (1973b). Questionnaire wording and translation. Cross cultural research methods (1. Bask1) içinde (32-58). Chicago: John Willey \& Sons, Inc.

Brislin, R. W., Lonner, W. J., \& Thorndike, R. M. (1973a). Cross cultural research methods. New York: John Willey\&Sons Pub.

Budnick, C. J., Rogers, A. P., \& Barber, L. K. (2020). The fear of missing out at work: Examining costs and benefits to employee health and motivation. Computers in Human Behavior, 104, 106161.

Büyüköztürk, Ş. (2005). Anket geliştirme. Türk Eğitim Bilimleri Dergisi, 3(2), 133-151.

Can, A. (2017). SPSS ile bilimsel araştırma sürecinde nicel veri analizi. Pegem yayıncılık.

Chen, F. F., West, S. G., \& Sousa, K. H. (2006). A comparison of bifactor and second-order models of quality of life. Multivariate Behavioral Research, 41(2), 189-225.

Deci, E. L., \& Ryan, R. M. (1985). Self-determination and intrinsic motivation in human behavior. Plenum Press, New York, NY.

Dossey, L. (2014). FOMO, digital dementia, and our dangerous experiment. Explore. The Journal of Science and Healing, 10(2), 69-73.

Eichhorn, B. R. (2014). Common method variance techniques. Cleveland State University, Department of Operations \& Supply Chain Management. Cleveland, OH: SAS Institute Inc, 1-11.

Eşitti, Ş. (2015). Bilgi çağında problemli internet kullanımı ve enformasyon obezitesi: Problemli internet kullanımı ölçeğinin üniversite öğrencilerine uygulanması, İstanbul Üniversitesi İletişim Fakültesi Dergisi, 49(2), 75-97.

Fornell, C., \& Larcker, D. F. (1981). Evaluating structural equation models with unobservable variables and measurement error. Journal of Marketing Research, 18(1), 39-50.

Gökler, M. E., Aydın, R., Ünal, E., \& Metintaş, S. (2016). Sosyal ortamlarda gelişmeleri kaçırma korkusu ölçeğinin Türkçe sürümünün geçerlilik ve güvenilirliğinin değerlendirilmesi. Anadolu Psikiyatri Dergisi, 17(1), 52-59.

Grolnick, W. S., Deci, E. L., \& Ryan, R. M. (1997). Internalization within the family: The selfdetermination theory perspective. In J. E. Grusec \& L. Kuczynski (Eds.), Parenting and children's internalization of values: A handbook of contemporary theory (pp. 135-161). New York: Wiley.

Gürbüz, S. (2019). Amos ile yapısal eșitlik modellemesi. Ankara: Seçkin Yayıncılık.

Gürbüz, S., \& Şahin, F. (2014). Sosyal bilimlerde araştırma yöntemleri. Ankara: Seçkin Yayıncılı.

Hair, J. F., Black, W. C., Babin, B. J., \& Anderson, R. E. (2014). Multivariate data analysis. Pearson new international edition. Essex: Pearson Education Limited.

Hu, L., Bentler, P.M. (1999), Cutoff Criteria for Fit Indexes in Covariance Structure Analysis: Conventional Criteria Versus New Alternatives, SEM, 6(1), 1-55.

Jöreskog, K. G., \& Sörbom, D. (1993). LISREL 8: Structural equation modeling with the SIMPLIS command language. Scientific Software International.

Kart, M. E., \& Güldü, Ö. (2008). Self-determination scale: The adaptation study. Ankara University Journal of Faculty of Educational Sciences, 41(2), 187-207.

Kline, R. B. (1998). Software review: Software programs for structural equation modeling: Amos, EQS, and LISREL. Journal of psychoeducational assessment, 16(4), 343-364.

Kline, R. B. (2015). Principles and practice of structural equation modeling. Guilford publications. 
Kline, R. B. (2015). Principles and practice of structural equation modeling. Guilford publications.

Kowal, J., \& Fortier, M. S. (1999). Motivational determinants of flow: Contributions from selfdetermination theory. The journal of social psychology, 139(3), 355-368.

Lavenda, D. (2016). Workplace fomo is real, and getting worse,(Erişim:02.06.2020), https://www.cmswire.c om/digital-workplace/workplace-fomo-is-real-andgetting-worse/.

Lilleoja, L., Dobewall, H., Aavik, T., Strack, M., \& Verkasalo, M. (2016). Measurement equivalence of Schwartz's refined value structure across countries and modes of data collection: New evidence from Estonia, Finland, and Ethiopia. Personality and Individual Differences, 102, 204-210.

Lozano, C. (2016). FOMO in the Workplace, (Erişim:20.06.2020), https://resources.datis.com/blo gs/fomo-in-the-workplace.

Milyavskaya, M., Saffran, M., Hope, N., \& Koestner, R. (2018). Fear of missing out: prevalence, dynamics, and consequences of experiencing FOMO. Motivation and Emotion, 42(5), 725-737.

Morgan, G. A., Leech, N. L., Gloeckner, G. W. ve Barret, K. C. (2004). SPSS for introductory statistics: Use and interpretation, Second Edition, Lawrance Erlbaum Associates: London.

Oxford Sözlük,

(Erişim:09.06.2020), https://www.oxfordlearnersdic tionaries.com/definition/english/fomo?q=FoMO.
Podsakoff, P. M., MacKenzie, S. B., Lee, J. Y., \& Podsakoff, N. P. (2003). Common method biases in behavioral research: a critical review of the literature and recommended remedies. Journal of applied psychology, 88(5), 879- 903.

Przybylski, A. K., Murayama, K., DeHaan, C. R., \& Gladwell, V. (2013). Motivational, emotional, and behavioral correlates of fear of missing out. Computers in Human Behavior, 29(4), 1841-1848.

Ryan, R. M., \& Deci, E. L. (2000). Self-determination theory and the facilitation of intrinsic motivation, social development, and well-being. American psychologist, 55(1), 68-78

Tabachnick, B. G., \& Fidell, L. S. (2013). Using multivariate statistics (6th ed.). Boston, MA: Pearson.

Taylor, K. (2014). The 'fomo epidemic' and why it matters to millennial-hungry businesses. (Erişim:02.06.2020), https://www.entrepreneur.com/ article/237566.

Wegmann, E., Oberst, U., Stodt, B., \& Brand, M. (2017). Online-specific fear of missing out and Internet-use expectancies contribute to symptoms of Internetcommunication disorder. Addictive Behaviors Reports, 5, 33-42.

Wiesner, L. (2017). Fighting FoMO: A study on implications for solving the phenomenon of the fear of missingout (Master'sthesis), University of Twente.

Yando, F. (2020), Indeed finds fomo a factor while ooo, (Erişim:02.06.2020), https://www.businesswire.com/ news/home/20150827005171/en/Finds-FOMOFactor-OOO\#.VeDU0rxVhBe. 


\section{Extended Summary}

\section{Introduction}

The commonly used general FoMO measure (i.e., Pryzbylski et al., 2013) includes elements specific to technology communication. However, current measures focus on situations related to friendships or individuals with no context in general (Pryzbylski et al., 2013). Given this situation, FoMO emerges in the workplace, although it is not fun, while transferring it to potentially rewarding business interactions in the context of employees. In the social media world, F0MO is a well-known phenomenon, but if it is in the workplace, FoMO is a new concept.

The workplace FoMO discusses how FoMO can influence work-related technology usage behavior. It is seen that the workplace FoMO overlaps with similar structures such as general FoMO, social anxiety and social comparison orientation, but it is argued that it is different from these concepts. The workplace FoMO shows that FoMO is related to the organizational commitment, participation and use of workrelated technology of the employees. In the literature, FoMO is generally based on Self-Determination Theory (Budnick, Rogers \& Barber, 2020). The purpose of Self-Determination Theory is to determine "the conditions that ensure healthy development of individuals, groups and societies". Theory can adopt the attitudes and behaviors that individuals encounter in the process of interaction and social relations. He also argues that it can internalize these attitudes and behaviors (Grolnick, Deci, \& Ryan, 1997). The need to be connected is people's need to be connected with others. It is people's feeling of belonging in their social environment and taking care of people (Kowal \& Fortier, 1999). Relationships meet the need to belong, according to Self-Determination Theory (Budnick, Rogers \& Barber, 2020).

In accordance with the Self-Determination Theory, individuals who have fear of missing out may want to blur the work-home boundaries and engage in work hours later to meet their social needs. When such employees also perceive fewer norms to set work-home boundaries, they may anticipate more positive attitudes towards work because employees think that blurring work-home boundaries is an acceptable part of workplace culture (Budnick, Rogers \& Barber, 2020).

The workplace FoMO is defined as "pervasive apprehension that, relative to other employees, one might miss valuable career opportunities when away or disconnected from work". The workplace FoMO emerges as fear of missing opportunities in rewarding experiences such as building professional relationships, gaining valuable information, and contributing to important corporate decisions and projects. One of the main reasons for FoMO in the workplace is the flow of notifications employees receive regularly throughout the day and the fear of missing important tasks and opportunities. With the entrance of generation $\mathrm{Y}$ into the business environment, it is now possible to encounter FoMO in the working environment. For this reason, the scale is needed to be adapted to Turkish.

\section{Method}

In the first stage, translation, in the second stage, pilot implementation, and in the third stage, validity and reliability processes were followed. Permission was obtained from the responsible author for the adaptation of the scale to Turkish. Translation, reverse translation and cultural adaptation study were conducted. Finally, pre-application and scale application and psychometric analysis were performed.

\section{Findings}

The validity and reliability analysis of the scale was conducted. EFA (Exploratory Factor Analysis) and CFA (Confirmatory Factor Analysis) were applied to test the structure bias of the scale. In this study, KMO (Kaiser-Meyer-Olkin) value was tested. As a result of the analysis, KMO value was found to be 0.90 and $(\mathrm{p}<.000)$ significant. The values of the items at the intersection point were found between 0.884 and 0.954 .

Using the Maximum Likelihood method, it was tested with alternative models whether the predicted structures of the scales were supported by the collected data (Gürbüz, 2019). Two different alternative models were compared using the $\chi^{2}$ difference tests of the predicted two-dimensional model (Twodimensional Informational and Relational, one-dimensional FoMO at Workplace). The first-order two-factor structure was found to be the best fitting model.

CR was preferred for the reliability of the dimensions of the workplace FoMO scale. It is accepted that the internal consistency coefficient of CR is a better alternative model than Cronbach Alpha (Kline, 2015). AVE, MSV and $\operatorname{MaxR}(\mathrm{H})$ values were calculated for the convergent and divergent validity. As a result of the analysis, $\sqrt{ }$ AVE values were found to be greater than the correlation between factors $(r=.710)$. It was also found that the $C R$ values were greater than the AVE value and the AVE value was greater than 0.5 .

When we tested whether the workplace FoMO differs according to age and gender, a significant relationship was observed according to age $(\mathrm{r}=-.257, \mathrm{p}=.000)$, but no significant relationship was observed according to gender $(\mathrm{r}=-.016, \mathrm{p}=$ .81). According to ANOVA test results, as the average age increases, the FoMO level decreases in the workplace $(\mathrm{F}=5.23$, $\mathrm{p}=$, 002). These findings are in line with the results of previous studies (Pryzbylski et al., 2013; Budnick, Rogers \& Barber, 2020).

\section{Discussion and Conclusion}

In this study, 10-item two-dimensional (Informational and Relational Exclusion) the workplace FoMO scale's (Budnick, Rogers \& Barber, 2020) reliability and validity were examined in the context of Turkey. There are two adaptation scales for general FoMO in the literature (Gökler et al., 2016; Balta et al., 2018). This adapted scale differs from two scales. The scales developed for general FoMO are mostly aimed at measuring the FoMO levels of young individuals. However, this scale is for the fear of missing out on developments in workplaces. General FoMO scales may not be suitable for employees in a business context. As the time spent in technology tools increases, the importance of studies about the fear of missing out on developments in the workplace increases. In addition, it is argued that the fear of missing out on developments in the workplace may arise as the generation Y enters the business life. This study has limitations such as the participants being selected from a single culture, being a cross-sectional study, having a social desirability effect, and collecting study data using a questionnaire. 


\title{
Ek-1
}

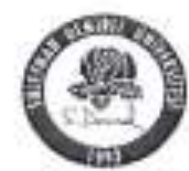

Sayı : 87432456,050,99

Konu : Etik Kurul Onay1.
T.C.

SẼLEYMAN DFMIREL CNIVERSITESİ RFKTÖRLËĞ

Sosyal ve Beşeri Bilimler

Etik Kurul Başkanhğı

\author{
Sayin Arş.Gor, Dr.Seyhan OzDEMiR \\ tktisadi ve Idari Bilimler Faksiltesi \\ Ognetim Gilovilisi
}

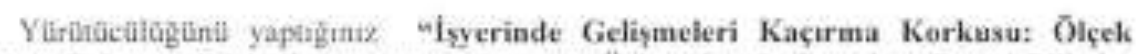

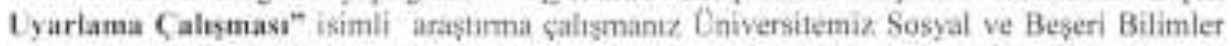
Etik Kuruluman 22.04.2020 taribli ve 90/7 sayil kararr ile uygun bulunumuştur.

Karann bir sureti yasma ekinde gónderilmis olup, ilgi hasvurunuza cevaten bilgilerinizi rica ederim.

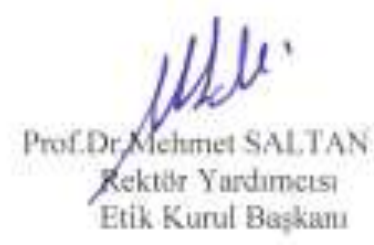

EKLER:

1. Zari 
Ek-2

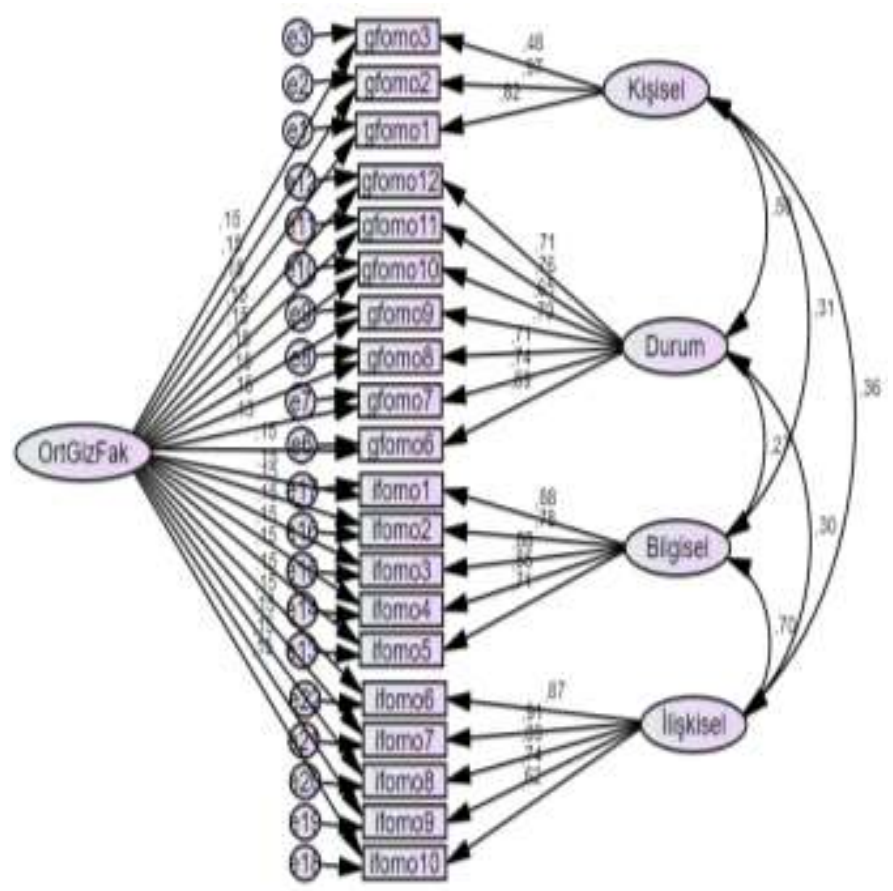

Şekil 4. Ortak Gizil Faktörler 